\title{
Annotations
}

\section{Trends in birth rate and the provision of paediatric services}

The absolute number of births a year depends both on the current fertility rate, and the number of women of childbearing age. During the last century changes in both factors led to sharp fluctuations, ranging from nearly 1000000 births in a year at the turn of the century to only 570000 in 1977 . The Figure illustrates these trends in terms of fertility rate and absolute numbers.

Fluctuations of this magnitude have considerable and very variable implications for the paediatric services, and some of the more important consequences will be discussed below.

\section{Effect on work load}

The effect of such fluctuations on work load depends both on the cumulative trend and the consequent total of children (defined here as under age 15) and on the year-to-year variation in births. The Table shows such variations within the last decade. Between 1971 and 1980 there has been an average fall of over $1 \%$ a year in the total number of children of less than 15 years in England and Wales. However this overall fall conceals sharper annual changes in numbers of births-for example a fall of $7.3 \%$, representing 51000 births between 1973 and 1974, and a rise of $8.4 \%$ representing 48000 births between 1978 and 1979 .
Table Population (thousands) under 15 years in England and Wales, 1971 to $1980^{7} 8$

\begin{tabular}{|c|c|c|c|c|c|}
\hline & $\begin{array}{l}<1 \\
\text { (as projected } \\
\text { in 1975) }\end{array}$ & $1-4$ & $5-9$ & $10-14$ & $\begin{array}{l}\text { All under } \\
\text { I5 }\end{array}$ \\
\hline $\begin{array}{l}1971 \\
1972 \\
1973 \\
1974 \\
1975\end{array}$ & $\begin{array}{c}779 \\
735 \\
692 \\
641 \\
615 \\
(616)\end{array}$ & $\begin{array}{l}3127 \\
3088 \\
3039 \\
2938 \\
2821\end{array}$ & $\begin{array}{l}4053 \\
4067 \\
4037 \\
3984 \\
3901\end{array}$ & $\begin{array}{l}3645 \\
3741 \\
3833 \\
3924 \\
4006\end{array}$ & $\begin{array}{ll}11 & 604 \\
11 & 631 \\
11 & 601 \\
11 & 487 \\
11 & 343\end{array}$ \\
\hline 1976 & $\begin{array}{c}586 \\
(585)\end{array}$ & 2660 & 3861 & 4036 & 11143 \\
\hline 1977 & $\begin{array}{c}559 \\
(570)\end{array}$ & 2512 & 3786 & 4047 & 10904 \\
\hline 1978 & $\begin{array}{c}569 \\
(568)\end{array}$ & 2389 & 3699 & 4019 & 10676 \\
\hline 1979 & $\begin{array}{c}617 \\
(578)\end{array}$ & 2320 & 3559 & 3977 & 10473 \\
\hline 1980 & $\begin{array}{c}639 \\
(603)\end{array}$ & 2322 & 3424 & 3904 & 10289 \\
\hline
\end{tabular}

The most immediate impact of such changes is on the work load generated by neonates-for instance the needs of low birthweight and sick infants-and on preventive medicine programmes-such as screening and immunisation. To take some simple examples, the sharp annual changes described will be reflected in the number of Guthrie tests performed, and in the number of doses of vaccine required in a

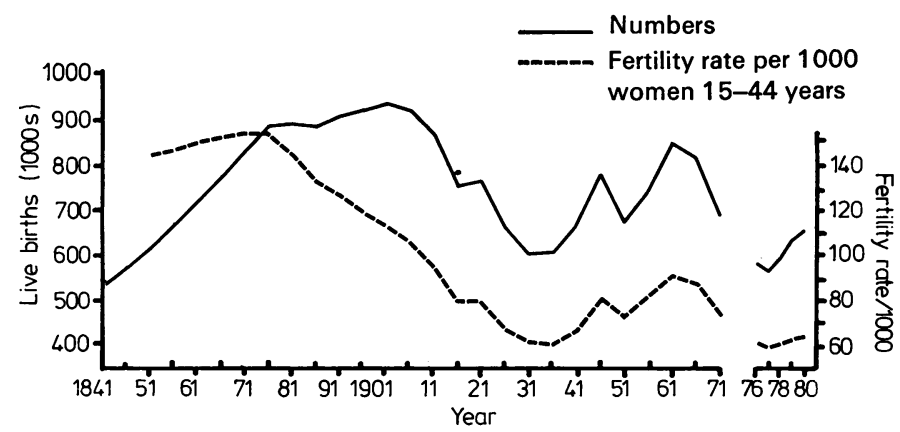

Figure Average numbers of births and fertility rate per year in England and Wales, 1841 to 1980 (quinquennial until 1976). 56 
year, as well as in the staff and equipment required for neonatal intensive care.

The demand for hospital admissions in infancy and childhood will also vary with the size of the annual cohort and with the cumulative sum of 15 consecutive cohorts. To give specific examples, the number of squint and hernia operations carried out in childhood could vary sharply from year to year, as could the number of children with the rare defects which nevertheless generate a great demand for very specialised medical care-for instance leukaemia, and other childhood cancers. The actual admission rate will also be influenced by trends in admission policy, and this too may be affected by the size of the child population.

This situation does not differ in principle from the problems faced in the planning for the medical care of adults, except that the age span of children is much smaller and far fewer staff and facilities are devoted to their care, so that the opportunity for 'buffering' the effect of short-term changes in population size is reduced. It follows that there must always be a certain amount of 'slack' in the provision for paediatric care, particularly neonatal care, where the impact of change is the greatest.

\section{Other effects of changing age distributions in childhood}

There are other, more subtle effects of variations in the annual number of births. Perhaps the most interesting is the effect on infectious disease transmission of changing the size of the susceptible pool of children from year to year. The possible effect of this has been estimated by the use of mathematical models. ${ }^{1}$ It will clearly vary from disease to disease, and with the immunity status of the older children.

Other effects may be on behaviour patterns with varying proportions of children of different ages and birth ranks in the community, and this could affect truancy and delinquency rates.

\section{Effects of changing demographic patterns in births}

Changes in the demographic background of births may affect needs for medical care as much, or even more, than changes in absolute numbers.

For instance since 1961 the proportion of births to mothers aged 40 to 44 or more has fallen by one-third to its present level of less than $1 \%$ of all births.
The effects of this and of other changes in maternal age structure on the incidence of Down's syndrome have been documented ${ }^{2} 3$ as have the effects of simultaneous changes in maternal age, parity, and social class on perinatal mortality. ${ }^{4}$ Such changes and others relevant to risk of mortality or morbiditysuch as illegitimacy - and changes in the distribution of social class or ethnic group at local or national level must be considered in conjunction with changes in absolute numbers of births in predicting the varying needs for medical care, for depending on their nature they may augment or reduce the needs.

It is of obvious importance that paediatricians and other child health professionals should be fully aware of current demographic changes in order to forecast future staffing, and long-term training needs, as well as short- and long-term hospital provision. Unfortunately population projections, particularly for births some years ahead, are often not sufficiently accurate for planning purposes (Table). It should become part of district medical officers' duties to keep the paediatricians informed in this respect, and to ensure that the planning of children's services is swiftly responsive to demographic change.

\section{References}

1 Stewart G T. Trends in epidemiology. Springfield, Ill: Thomas, 1972: 379.

2 Wynne Griffith G. The prevention of Down's syndrome (mongolism). Health Trends 1973; 5: 59-60.

3 Alberman E. The prevention of Down's syndrome. Dev Med Child Neurol 1975; 17 : 793-5.

4 Hellier J. Perinatal mortality, 1950 and 1973. In: Population Trends No 9. London: HMSO, 1977: 13-5.

5 Registrar General. Statistical review of England and Wales Annual Reports. Part II. Tables; population. London: HMSO, up to 1974.

6 Office of Population Censuses and Surveys. Mortality statistics: childhood and maternity. Annual reports. Series DH3 No 4. London: HMSO, from 1974.

7 In: Population trends No 26. London: HMSO, 1981 : 30.

8 Office of Population Censuses and Surveys. Population projections 1975-2015. Series PP2 No 7. London: HMSO, 1977.

Eva Alberman Department of Clinical Epidemiology, London Hospital Medical College, Turner Street, London E1 2AD 